\section{The support your patients need}

Oral hygiene might not have been top of the agenda for many in recent months, but it's vital to remind patients of its importance.

Why not help your patients make the most of leading solutions from Curaprox with the new Home Oral Care Kit? The cost-effective package includes a CS 5460 toothbrush, a CPS Interdental Starter Kit and a tube of Enzycal Toothpaste, with added value provided by a free bottle of hospital-grade hand sanitiser.

Your patients will also receive an extra $10 \%$ off when they submit your practice code at the checkout, and we will give your practice $10 \%$ commission to say thank you.

Don't forget, the CS 5460 manual toothbrush features ultra-soft CUREN filaments that deliver an effective yet gentle clean, while the CPS Prime range of interdental brushes is easy to use caters to the varying needs of individuals.

For more information and to get your unique $10 \%$ offer code, call 01480862084 email info@curaprox.co.uk or visit www. curaprox.co.uk.

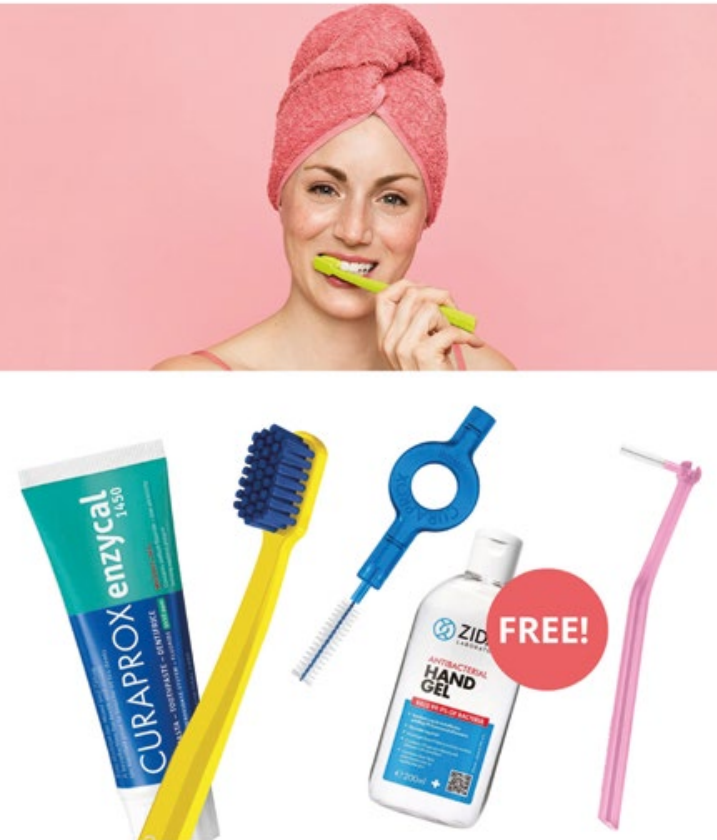

\title{
A solid start to dental implantology
}

For anyone considering a new venture for the next chapter of their dental career, the PG Cert in Implant Dentistry will provide a solid foundation to get started in the field.

Delivered through Ucer Education and led by Specialist Oral Surgeon, Professor Cemal Ucer, the 12-month modular course combines both theoretic and practical training for a comprehensive learning experience, followed by clinical training under supervision at the centre. A highly experienced training faculty cover a wide range of relevant topics, enabling delegates to work towards their EduQual Level 7 qualification.

Complemented by the exceptional facilities at the Centre of OralMaxillofacial and Dental
Implant Reconstruction in Manchester and the ICE Postgraduate Hospital, the next cohort starts in November.

For more information on the PG Cert in Implant Dentistry from Ucer Education supported by Geistlich, Megagen, Neoss, TRI Implants and General Medical - visit www.ucer.education or contact Prof Ucer at ice@ucer.uk

\section{New PPE website launched}

As a global leader in the manufacture of PPE, 3M Oral Care has now launched a dedicated website providing more information on the products you need to keep safe.

Solutions available for dental professionals include:

$\rightarrow$ 3M Aura Particulate Health Respirator FFP2, Type IIR 1862+

$\rightarrow 3 \mathrm{M}$ Aura Disposable Health Respirator FFP3, Type IIR, 1863+

$\rightarrow$ Surgical Mask 1826
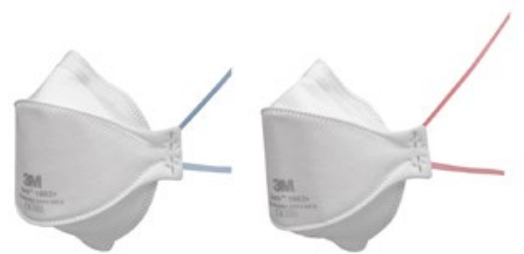

$\rightarrow$ Splash Resistant Surgical Mask 1820S

$\rightarrow$ 3M Triple Layer Molded face Mask 2042F

$\rightarrow 3 \mathrm{M}$ Cavilon No Sting Barrier Film

$\rightarrow 3 \mathrm{M}$ Comply SteriGage Integrating Indicator

Useful information and details of each product can be found on the easy-tonavigate website. For more information, or to request a video call with your local representative, call 08705360036 or visit 3M.co.uk/dental-ppe.
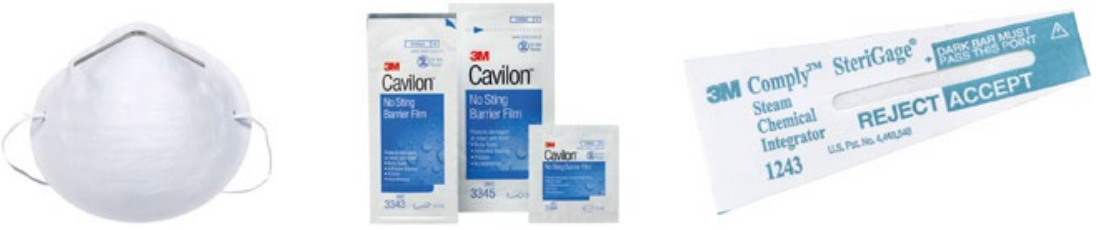